\title{
Characteristics of Gelation by Amides based on trans-1,2-Diaminocyclohexane: The Importance of Different Substituents
}

\author{
Haruka Nakagawa, ${ }^{1}$ Mamoru Fujiki, ${ }^{1}$ Takaaki Sato, ${ }^{1}$ Masahiro Suzuki, ${ }^{2}$ Kenji Hanabusa*2,3 \\ ${ }^{1}$ Faculty of Textile Science \& Technology, Shinshu University, Ueda, 386-8567 Japan \\ 2 Interdisciplinary Graduate School of Science \& Technology, Shinshu University, Ueda, 386-8567 Japan \\ ${ }^{3}$ Division of Frontier Fibers, Institute for Fiber Engineering, ICCER, Shinshu University, Ueda, 386-8567 Japan \\ E-mail: hanaken@shinshu-u.ac.jp
}

\begin{abstract}
Six diamides were prepared from trans- $(1 R, 2 R)$ 1,2-diaminocyclohexane and the corresponding racemate and were subsequently used as gelators. Three chiral compounds and their racemates were prepared. One of the chiral compounds and its racemate contained two $n$-dodecanoylamino groups as the same substituents. The other two chiral compounds and their racemates contained different substituents: 10-undecenoylamino and 2-heptylundecanoylamino groups, and 5-hydroxypentanoylamino and 2-heptylundecanoylamino groups. Their gelation abilities were evaluated on the basis of the minimum gel concentration using eight solvents. The thermal stability and transparency of the gels were investigated by UV-vis spectroscopy using three-component mixed solvents of hexadecyl 2-ethylhexanoate, liquid paraffin, and decamethyl cyclopentasiloxane (66 combinations). The gel-to-sol phase-transition temperatures were also studied. The viscoelastic behavior of the gels was studied by rheology measurements in the strain sweep mode. Aggregates constructing three-dimensional networks were studied by transmission electron microscopy and circular dichroism spectroscopy. The molecular packing of the gels was evaluated by small angle X-ray scattering (SAXS).
\end{abstract}

\section{Introduction}

Recently, low-molecular-weight gelators have attracted special attention because large volumes of solvent can often be immobilized by very small amounts of such compounds. With advances in supramolecular chemistry, numerous reports on gelators have been published in recent years. ${ }^{1-22}$ Another reason for researchers' interest in gelators lies in their potential industrial applications. Various compounds have been developed as gelators for use in cooking oils, spilled crude oil, cosmetics, aromatic compounds, ink thickeners, and greases. For example, 12-hydroxystearic acid ${ }^{23}$ has been practically used as a gelator for cooking oil. As other examples, the $(1,3: 2,4)$-dibenzylidenesorbitol ${ }^{24}$ and the $\alpha, \gamma$-bis- $n$-butylamide of $N$-lauroyl-L-glutamic acid are used in antiperspirants, and aromatic diureas are used in synthetic greases.

Physical gelation by low-molecular-weight compounds results from noncovalent bonds, such as hydrogen bonding, electrostatic interaction, van der Waals interaction, and $\pi-\pi$ interaction. During a gelation process, gelator molecules are first self-assembled during a cooling process, producing fibrous assemblies. These fibrous assemblies form a three-dimensional network structure, and gelation occurs as solvent molecules are trapped in the network.

Physical gelation by a gelator can usually be best understood as resulting from competition between a gelator's tendency to dissolve via solvation and its tendency to self-assemble and crystallize. That is, gels formed by gelators are reasonably assumed to be metastable materials that are formed preceding crystallization. Despite recent advances, designing a gelator is a formidable challenge, if not impossible. An effective approach to prevent the transformation from a metastable gel to a crystalline state has not been developed yet. Several other questions associated with the design of gelators remain unanswered. For instance, why do gelators in fluids form metastable gels instead of thermally stable crystals and what are the necessary and sufficient requirements, if any, for designing gelators? Notably, most of the reported gelators have a chiral carbon center in their structure, although exceptions are known. ${ }^{25-30}$ We previously synthesized several types of gelators from chiral compounds and observed that the corresponding racemates tend to crystallize rather than form gels. ${ }^{31-33}$ This behavior is explained by Wallach's rule ${ }^{34,35}$; specifically, racemic crystals tend to be denser than their chiral counterparts and the former is more stable than the latter. Despite racemic compounds being generally less expensive than chiral compounds, racemates are unfortunately unsuitable for use as gelators because of Wallach's rule. Resolving this apparent contradiction requires the development of a method to prevent the denser packing of molecules in racemates.

In the present paper, we focus on diamides derived from trans-1,2-diaminocyclohexane and study the effect of different substituents on the diamides' gelation abilities. We attached different substituents onto racemic trans-1,2diaminocyclohexane with the expectation that the different substituents would prevent denser packing, resulting in physical gelation. The incorporation of different substituents may lead to new gelators if disordered molecular packing occurs.

\section{Experimental}

\subsection{Instrumentation}

Elemental analysis was performed with a Perkin-Elmer 240B analyzer. Infrared spectra were recorded on a Jasco FTIR-7300 spectrometer using $\mathrm{KBr}$ plate. UV-vis and $\mathrm{CD}$ 
spectra were recorded on a Jasco V-570UV/VIS/NIR and a Jasco J-600, respectively. Transmission electron microscopy (TEM) and field emission SEM (FE-SEM) were done with a JEOL JEM-SS and a Hitachi S-5000, respectively. Rheology was measured by an Elquest Rheologia A300.

\subsection{Gelation test}

Gelation test was carried out by an upside-down test tube method. A typical procedure is as follows: A weighed sample and $1 \mathrm{~mL}$ of solvent in a septum-capped test tube with internal diameter of $14 \mathrm{~mm}$ was heated until the solid dissolved. The resulting solution was cooled at $25^{\circ} \mathrm{C}$ for $2 \mathrm{~h}$ and then the gelation was checked visually. When no fluid ran down the wall of the test tube upon inversion of the test tube, we judged it to be gel. The gelation ability was evaluated by the minimum gel concentration of a gelator necessary for gelation at $25^{\circ} \mathrm{C}$. The unit is $\mathrm{g} \mathrm{L}^{-1}$ (gelator/solvent). The solvents used for gelation test were ethyl acetate, isopropyl myristate, $\gamma$-butyrolactone, toluene, liquid paraffin, silicone oil (KF-54), decamethyl cyclopentasiloxane (D5), and hexadecyl 2-ethylhexanoate.

\subsection{Synthesis}

trans-(1R, 2R)-(-)-1,2-Diaminocyclohexane and racemic trans-1,2-diaminocyclohexane were purchased from Tokyo Chemical Industry Co. Ltd.

trans-(1R, 2R)-1-Boc-amino-2-aminocyclohexane: ${ }^{36}$ The 800 $\mathrm{mL}$ of methanol containing $16.53 \mathrm{~g}(0.453 \mathrm{~mol})$ of dry $\mathrm{HCl}$ was added dropwise to the solution of $51.78 \mathrm{~g}(0.453 \mathrm{~mol})$ of trans-(1R, 2R)-(-)-1,2-diaminocyclohexane in $80 \mathrm{~mL}$ of methanol for $2 \mathrm{~h}$. After adding $50 \mathrm{~mL}$ of water, $98.97 \mathrm{~g}(0.453$ mol) of di-t-butyl dicarbonate was added by portions for $1 \mathrm{~h}$. The mixture was stirred for $2 \mathrm{~h}$, and then methanol was removed. The residue was rinsed with $900 \mathrm{~mL}$ of ether and the insoluble matter was filtered off, dried. The crude product was dissolved in $800 \mathrm{~mL}$ of water and then extracted with a mixture of $500 \mathrm{~mL}$ of $\mathrm{CH}_{2} \mathrm{Cl}_{2}$ and $340 \mathrm{~mL}$ of $2 \mathrm{M} \mathrm{NaOH}$. The organic layer was picked up and treated with $\mathrm{MgSO}_{4}$, evaporated. The recrystallization from $900 \mathrm{~mL}$ of ligroin gave $67.87 \mathrm{~g} \mathrm{(70 \% )} \mathrm{of}$ trans- $(1 R, 2 R)$-1-Boc-amino-2-aminocyclohexane. IR $(\mathrm{KBr}$, $\left.\mathrm{cm}^{-1}\right): 1695$ ( $\mathrm{vC}=\mathrm{O}$ urethane), $1554(\delta \mathrm{N}-\mathrm{H}$ amide II).

$(\boldsymbol{R}, \boldsymbol{R})-1$ : A solution of $34.07 \mathrm{~g}(0.159 \mathrm{~mol})$ of trans $-(1 R$, $2 R)$-1-Boc-amino-2-aminocyclohexane and $26.1 \mathrm{~mL}(0.238$ $\mathrm{mol}$ ) of $\mathrm{N}$-methylmorpholine in $300 \mathrm{~mL}$ of dry THF was cooled in ice-water bath, and then $48.16 \mathrm{~g}(0.159 \mathrm{~mol})$ of 2-heptylundecanoyl chloride was added drop-by-drop. The mixture was stirred for $1 \mathrm{~h}$ in ice-water bath, followed by for 3 $\mathrm{h}$ at room temperature. A filtrate without $\mathrm{NEt}_{3} / \mathrm{HCl}$ salt was evaporated and recrystallized from a mixture of $650 \mathrm{~mL}$ of ethyl acetate and $250 \mathrm{~mL}$ of hexane. Yield; $71.78 \mathrm{~g}(94 \%)$. IR $\left(\mathrm{KBr}, \mathrm{cm}^{-1}\right): 1690(\mathrm{vC}=\mathrm{O}$ urethane $), 1644(\mathrm{vC}=\mathrm{O}$ amide $\mathrm{I})$, $1520(\delta \mathrm{N}-\mathrm{H}$ amide $\mathrm{II})$.

$(\boldsymbol{R}, \boldsymbol{R})$-2: One hundred thirty $\mathrm{mL}$ of $25 \% \mathrm{HBr} / \mathrm{AcOH}$ was added to $34.07 \mathrm{~g}(0.159 \mathrm{~mol})$ of $(\boldsymbol{R}, \boldsymbol{R})-\mathbf{1}$ in $100 \mathrm{~mL}$ of acetic acid and stirred overnight. After completely removing $\mathrm{HBr} / \mathrm{AcOH}, 400$ $\mathrm{mL}$ of ether was added to the resulting oily product and cooled. The oil was converted crystals. Yield; $66.25 \mathrm{~g}(96 \%)$. IR (KBr, $\left.\mathrm{cm}^{-1}\right)$ : $1644(\mathrm{vC}=\mathrm{O}$ amide I), $1525(\delta \mathrm{N}-\mathrm{H}$ amide II $)$.

$(\boldsymbol{R}, \boldsymbol{R})$-C12C18: A solution of $2.00 \mathrm{~g}(4.33 \mathrm{mmol})$ of $(\boldsymbol{R}, \boldsymbol{R})-\mathbf{2}$ and $0.88 \mathrm{~g}(8.67 \mathrm{mmol})$ of triethylamine in $60 \mathrm{~mL}$ of dry THF was cooled in ice-water bath, and then $1.04 \mathrm{~g}(4.77 \mathrm{mmol})$ of $n$-dodecanoyl chloride was added drop-by-drop. The mixture was stirred for $3 \mathrm{~h}$ at room temperature. A hundred $\mathrm{mL}$ of water was added to the reaction mixture and a precipitate was filtered off and dried. Recrystallization from a mixture of $200 \mathrm{~mL}$ of ethyl acetate and $100 \mathrm{~mL}$ of hexane gave $2.18 \mathrm{~g}(89 \%)$ of the product. IR $\left(\mathrm{KBr}, \mathrm{cm}^{-1}\right)$ : $3282(\mathrm{vN}-\mathrm{H}), 1635(\mathrm{vC}=\mathrm{O}$ amide I), 1544 ( $\delta \mathrm{N}-\mathrm{H}$ amide II). Found: C 76.49 H 13.07, N 4.91\%.
Calcd for $\mathrm{C}_{36} \mathrm{H}_{70} \mathrm{~N}_{2} \mathrm{O}_{2}$ : C 76.81, H 12.53, N 4.98\%. ${ }^{1} \mathrm{H}-\mathrm{NMR}$ $\left(400 \mathrm{MHz}, \mathrm{CDCl}_{3}, \mathrm{TMS}, 25^{\circ} \mathrm{C}\right): \delta=5.95(\mathrm{~d}, 1 \mathrm{H}, \mathrm{J}=6.52 \mathrm{~Hz}$, $\mathrm{NH}-\mathrm{CO}), 5.90$ (d, 1H, J = 6.84 Hz, NH-CO), 3.59-3.70 (m, 2H, $\left.-\mathrm{NH}-\mathrm{C} \underline{\mathrm{H}}\left(\mathrm{CH}_{2}\right)-\mathrm{C} \underline{\mathrm{H}}\left(\mathrm{CH}_{2}\right)-\mathrm{NH}-\right), \quad 1.72-2.12 \quad(\mathrm{~m}, \quad 7 \mathrm{H}$, $-\mathrm{CO}-\mathrm{C} \underline{\mathrm{H}} \mathrm{CH}_{2}\left(\mathrm{CH}_{2}\right)-$,

$-\mathrm{CO}-\mathrm{CH}_{2} \mathrm{CH}_{2}-$, cyclohexane- $\left.\mathrm{CH}_{2}-\left(\mathrm{CH}_{2}\right)_{2}-\mathrm{CH}_{2}-\right)$, 1.24-1.59 (br, 50H, alkyl, cyclohexane- $\left.\mathrm{CH}_{2}-\mathrm{CH}_{2}-\right), 0.85-0.89\left(\mathrm{~m}, 9 \mathrm{H},-\mathrm{CH}_{2} \mathrm{CH}_{3}\right)$.

Racemic trans-1-Boc-amino-2-aminocyclohexane: This compound was prepared from racemic trans-1,2-diaminocylohexane by the similar procedure described above. Yield; 77\%. IR $\left(\mathrm{KBr}, \mathrm{cm}^{-1}\right): 1682(\mathrm{vC}=\mathrm{O}$ urethane), 1517 ( $\delta \mathrm{N}-\mathrm{H}$ amide II). Found: C 61.68, H 10.73, N 13.16\%. Calcd for $\mathrm{C}_{11} \mathrm{H}_{22} \mathrm{~N}_{2} \mathrm{O}_{2}$ : C 61.65, H 10.35, N 13.07\%.

rac-1: This compound was prepared from racemic trans-1-Boc-amino-2-aminocylohexane by the similar procedure described in $(\boldsymbol{R}, \boldsymbol{R})-\mathbf{1}$. Yield; $93 \%$. IR $\left(\mathrm{KBr}, \mathrm{cm}^{-1}\right)$ : $1696(v \mathrm{C}=\mathrm{O}$ urethane $), 1638(v \mathrm{C}=\mathrm{O}$ amide $\mathrm{I}), 1528(\delta \mathrm{N}-\mathrm{H}$ amide II). Found: C 72.71, H 12.0, N 5.79\%. Calcd for $\mathrm{C}_{29} \mathrm{H}_{56} \mathrm{~N}_{2} \mathrm{O}_{3}$ : C 72.45, H 11.74, N 5.83\%.

rac-2: This compound was prepared from rac-1 by the similar procedure described in $(\boldsymbol{R}, \boldsymbol{R})-2$. Yield; $94 \%$. IR $\left(\mathrm{KBr}, \mathrm{cm}^{-1}\right)$ : $1644(v \mathrm{C}=\mathrm{O}$ amide I), 1525 ( $\delta \mathrm{N}-\mathrm{H}$ amide II). Found: $\mathrm{C} 62.19$ $\mathrm{H} 10.83$, N 6.22\%. Calcd for $\mathrm{C}_{24} \mathrm{H}_{49} \mathrm{~N}_{2} \mathrm{OBr}$ : C 62.45, H 10.70, N 6.07\%.

rac-C12C18: This compound was prepared from rac-2 by the similar procedure described in $(\boldsymbol{R}, \boldsymbol{R})-\mathbf{C 1 2 C 1 8}$. Yield; $94 \%$. IR $\left(\mathrm{KBr}, \mathrm{cm}^{-1}\right): 3282(v \mathrm{~N}-\mathrm{H}) 1635(v \mathrm{C}=\mathrm{O}$ amide $\mathrm{I}), 1544(\delta \mathrm{N}-\mathrm{H}$ amide II). Found: C $76.50 \mathrm{H} 12.77, \mathrm{~N} 5.01 \%$. Calcd for $\mathrm{C}_{36} \mathrm{H}_{70} \mathrm{~N}_{2} \mathrm{O}_{2}$ : C 76.81, H 12.53, N 4.98\%. ${ }^{1} \mathrm{H}-\mathrm{NMR}(400 \mathrm{MHz}$, $\mathrm{CDCl}_{3}$, TMS, $\left.25^{\circ} \mathrm{C}\right): \delta=6.03(\mathrm{~d}, 1 \mathrm{H}, \mathrm{J}=6.56 \mathrm{~Hz}, \mathrm{NH}-\mathrm{CO})$, $5.96(\mathrm{~d}, 1 \mathrm{H}, \mathrm{J}=6.88 \mathrm{~Hz}, \mathrm{NH}-\mathrm{CO}), 3.59-3.69(\mathrm{~m}, 2 \mathrm{H}$, $\left.-\mathrm{NH}-\mathrm{C} \underline{\mathrm{H}}\left(\mathrm{CH}_{2}\right)-\mathrm{C} \underline{\mathrm{H}}\left(\mathrm{CH}_{2}\right)-\mathrm{NH}-\right), \quad 1.72-2.12 \quad(\mathrm{~m}, \quad 7 \mathrm{H}$, $-\mathrm{CO}-\mathrm{CHCH}_{2}\left(\mathrm{CH}_{2}\right)-$, $\quad-\mathrm{CO}-\mathrm{CH}_{2} \mathrm{CH}_{2}$, cyclohexane- $\left.\underline{\mathrm{C}}_{2}-\left(\mathrm{CH}_{2}\right)_{2}-\underline{\mathrm{CH}}_{2}-\right)$, 1.24-1.59 (br, 50H, alkyl, cyclohexane- $\left.\underline{\mathrm{C}}_{2}-\mathrm{CH}_{2}-\right), 0.85-0.89$ (m, 9H, $\left.-\mathrm{CH}_{2} \underline{\mathrm{CH}}_{3}\right)$.

$(\boldsymbol{R}, \boldsymbol{R})$-C5H18: A solution of $2.90 \mathrm{~g}(6.23 \mathrm{mmol})$ of $(\boldsymbol{R}, \boldsymbol{R})-\mathbf{2}$ and $100 \mathrm{~mL}$ of dichloromethane was shaken with $100 \mathrm{~mL}$ of 4 $\mathrm{M} \mathrm{NaOH}$ in a separating funnel. The organic layer was treated with $\mathrm{MgSO}_{4}$ and evaporated. Recrystallization from $2 \mathrm{~mL}$ of ligroin gave $2.20 \mathrm{~g} \quad(92 \%)$ of trans-(1R, 2R)-1-amino-2-(2-heptylundecanoylamino)cyclohexane. To a solution of $1.50 \mathrm{~g} \quad(3.94 \mathrm{mmol})$ of trans $-(1 R$, $2 R$ )-1-amino-2-(2-heptylundecanoylamino)cyclohexane in 30 $\mathrm{mL}$ of dry THF, $0.423 \mathrm{~mL}(3.94 \mathrm{mmol})$ of $\delta$-valerolactone was added and refluxed overnight. The precipitated matter after cooling the reaction mixture was filtered off, washed with hexane. Recrystallization from a mixture of $25 \mathrm{~mL}$ of ethyl acetate and $15 \mathrm{~mL}$ of hexane gave $1.63 \mathrm{~g}(86 \%)$ of $(\boldsymbol{R}$, R)-C5H18. IR (KBr, cm $\left.{ }^{-1}\right): 3407(v \mathrm{O}-\mathrm{H}), 3283(v \mathrm{~N}-\mathrm{H}), 1635$ ( $\mathrm{vC}=\mathrm{O}$ amide I), $1543(\delta \mathrm{N}-\mathrm{H}$ amide $\mathrm{II})$. Found: $\mathrm{C} 72.19, \mathrm{H}$ 12.17 , N 5.66\%. Calcd for $\mathrm{C}_{2}{ }_{2} \mathrm{H}_{56} \mathrm{~N}_{2} \mathrm{O}_{3}$ : C $72.45, \mathrm{H} 11.74, \mathrm{~N}$ $5.83 \%$.

rac-C5H18: This compound was prepared from racemic trans-1-amino-2-(2-heptylundecanoylamino)cyclohexane via rac-2 by the similar procedure described above. Recrystallization from a mixture of $80 \mathrm{~mL}$ of acetone and 20 $\mathrm{mL}$ of methanol gave the product in a yield of $78 \%$. IR $(\mathrm{KBr}$, $\left.\mathrm{cm}^{-1}\right)$ : $3407(\mathrm{vO}-\mathrm{H}), 3283(\mathrm{vN}-\mathrm{H}), 1636(\mathrm{vC}=\mathrm{O}$ amide $\mathrm{I}), 1543$ $(\delta \mathrm{N}-\mathrm{H}$ amide II). Found: C 72.69, H 12.29, N 5.83\%. Calcd for $\mathrm{C}_{29} \mathrm{H}_{56} \mathrm{~N}_{2} \mathrm{O}_{3}$ : C 72.45, H 11.74, N 5.83\%.

$(\boldsymbol{R}, \boldsymbol{R})-\mathbf{C 1 2 C 1 2}$ : A solution of $1.19 \mathrm{~g}(10.4 \mathrm{mmol})$ of trans-(1R, $2 R)$-(-)-1,2-diaminocyclohexane and $2.11 \mathrm{~g}(20.9 \mathrm{mmol})$ of triethylamine in $300 \mathrm{~mL}$ of dry THF was cooled in ice-water bath, and then $4.57 \mathrm{~g}(20.9 \mathrm{mmol})$ of $n$-dodecanoyl chloride was added drop-by-drop. The mixture was stirred for $3 \mathrm{~h}$ at room temperature. Twenty $\mathrm{mL}$ of acetone was added to the 
reaction mixture and a precipitate was filtered off and washed with water. Recrystallization from $100 \mathrm{~mL}$ of chloroform gave $4.20 \mathrm{~g}(92 \%)$ of the product. IR $\left(\mathrm{KBr}, \mathrm{cm}^{-1}\right): 3283(\mathrm{vN}-\mathrm{H})$, $1639(v \mathrm{C}=\mathrm{O}$ amide I), $1546(\delta \mathrm{N}-\mathrm{H}$ amide II). Found: $\mathrm{C} 75.28$, $\mathrm{H} 13.00, \mathrm{~N} 6.04 \%$. Calcd for $\mathrm{C}_{32} \mathrm{H}_{62} \mathrm{~N}_{2} \mathrm{O}_{2}$ : C 75.26, $\mathrm{H} 12.21, \mathrm{~N}$ $5.85 \%$. ${ }^{1} \mathrm{H}-\mathrm{NMR}\left(400 \mathrm{MHz}, \mathrm{CDCl}_{3}\right.$, TMS, $\left.25^{\circ} \mathrm{C}\right): \delta=5.88(\mathrm{~d}$, $2 \mathrm{H}, \quad \mathrm{J}=6.56 \mathrm{~Hz}, \quad \mathrm{NH}-\mathrm{CO}), 3.62-3.67(\mathrm{~m}, 2 \mathrm{H}$, $\left.-\mathrm{NH}-\mathrm{C} \underline{\mathrm{H}}\left(\mathrm{CH}_{2}\right)-\mathrm{C} \underline{\mathrm{H}}\left(\mathrm{CH}_{2}\right)-\mathrm{NH}-\right), \quad 1.73-2.17 \quad(\mathrm{~m}, \quad 8 \mathrm{H}$, -CO- $\underline{\mathrm{CH}}_{2}-\mathrm{CH}_{2}-$, cyclohexane- $\left.\underline{\mathrm{CH}}_{2}-\right), \quad 1.55-1.58 \quad(\mathrm{~m}, \quad 4 \mathrm{H}$, - $\mathrm{CO}-\mathrm{CH}_{2}-\mathrm{CH}_{2}-$ ), 1.15-1.35 (br, $36 \mathrm{H}$, alkyl), 0.87 (t, $6 \mathrm{H}, \mathrm{J}=$ $\left.13.72,-\mathrm{CH}_{2} \underline{\mathrm{CH}}_{3}\right)$.

ra-C12C12: This compound was prepared from racemic trans-1,2-diaminocyclohexane by the similar procedure described above. Yield; 84\%. IR $\left(\mathrm{KBr}, \mathrm{cm}^{-1}\right): 3300(\mathrm{vN}-\mathrm{H})$, $1636(v \mathrm{C}=\mathrm{O}$ amide I), $1542(\delta \mathrm{N}-\mathrm{H}$ amide II). Found: $\mathrm{C} 75.22$, $\mathrm{H} 12.98, \mathrm{~N} 6.08 \%$. Calcd for $\mathrm{C}_{32} \mathrm{H}_{62} \mathrm{~N}_{2} \mathrm{O}_{2}$ : C 75.26, $\mathrm{H} 12.21, \mathrm{~N}$ $5.85 \% .{ }^{1} \mathrm{H}-\mathrm{NMR}\left(400 \mathrm{MHz}, \mathrm{CDCl}_{3}\right.$, TMS, $\left.25^{\circ} \mathrm{C}\right): \delta=5.91(\mathrm{~d}$, $2 \mathrm{H}, \quad \mathrm{J}=6.52 \mathrm{~Hz}, \mathrm{NH}-\mathrm{CO}), \quad 3.59-3.69(\mathrm{~m}, \quad 2 \mathrm{H}$, $\left.-\mathrm{NH}-\mathrm{C} \underline{\mathrm{H}}\left(\mathrm{CH}_{2}\right)-\mathrm{C} \underline{\mathrm{H}}\left(\mathrm{CH}_{2}\right)-\mathrm{NH}-\right), \quad 2.00-2.16 \quad(\mathrm{~m}, \quad 8 \mathrm{H}$, - $\mathrm{CO}-\underline{\mathrm{C}}_{2}-\mathrm{CH}_{2}-$, cyclohexane- $\left.\underline{\mathrm{CH}}_{2}-\right), \quad 1.55-1.58 \quad(\mathrm{~m}, \quad 4 \mathrm{H}$, - $\mathrm{CO}-\mathrm{CH}_{2}-\mathrm{CH}_{2}-$ ), 1.19-1.44 (br, $36 \mathrm{H}$, alkyl), 0.87 (t, $6 \mathrm{H}, \mathrm{J}=$ 13.64, $\left.-\mathrm{CH}_{2} \mathrm{CH}_{3}\right)$.

\subsection{SAXS}

Small angle X-ray scattering was recorded on an Anton Paar SAXS. The accessible $q$-range was between 0.06 and 28 $\mathrm{nm}^{-1}$. The preheated gel sample was poured into a cylindrical quartz cell having a diameter of $1 \mathrm{~mm}$ and the measurement was started after standing for $1 \mathrm{~h}$. A line-shaped monochromatic primary beam $(\mathrm{Cu} \mathrm{K} \alpha$ radiation, $\lambda=0.1542$ $\mathrm{nm})$ was irradiated to the gel samples and the solvent. The background contributions from capillary and solvent were corrected. Since the scattering intensity from the gel sample was rapidly converged to that of the solvent in the high- $q$ range of $q>10 \mathrm{~nm}^{-1}$, we discuss the corrected scattering patterns of the gel samples observed in $0.06<q / \mathrm{nm}^{-1}<10$ in a practical manner. A model independent collimation correction was made by relying on the Lake algorithm. ${ }^{37}$ The scattering intensity of the gel samples were finally obtained on an absolute scale by referring to the forward intensity of the secondary standard (water). ${ }^{38}$

\subsection{Gelation abilities}

\section{Results and Discussion}

We prepared six diamides derived from trans-1,2diaminocyclohexane, as shown in Scheme 1. The chiral species containing the different substituents-specifically, trans-(1R,2R)-1-(dodecanoylamino)-2-(2-heptylundecanoylami no)cyclohexane-is abbreviated as $(\boldsymbol{R}, \boldsymbol{R})$-C12C18. The corresponding racemate, which was prepared from racemic

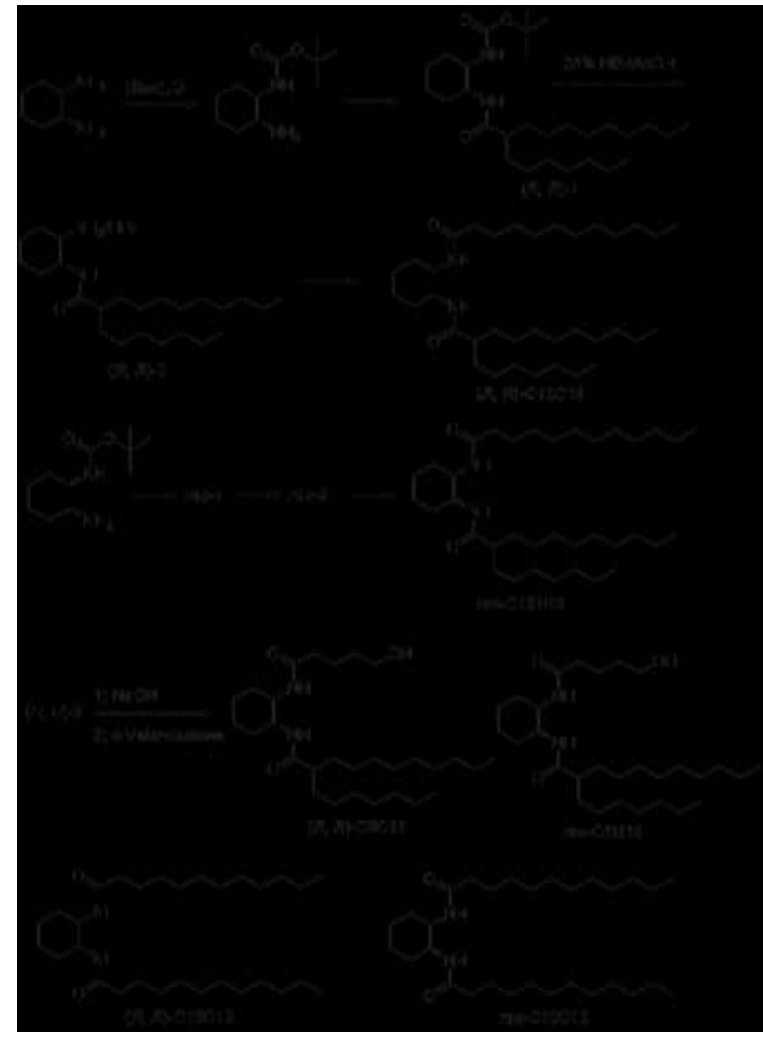

Scheme 1. Structures of gelators.

trans-1,2-diaminocyclohexane, is abbreviated as rac-C12C18. The chiral compound containing 5-hydroxypentanoylamino and 2-heptylundecanoylamino groups is abbreviated as $(\boldsymbol{R}$, $\boldsymbol{R}$ )-C5H18. The corresponding racemate is abbreviated as rac-C5H18. The chiral and racemate containing two $n$-dodecanoylamino groups as the same substituents are denoted as $(\boldsymbol{R}, \boldsymbol{R})-\mathbf{C 1 2 C 1 2}$ and rac-C12C12, respectively.

One objective of the present study is to develop gelators based on racemic trans-1,2-diaminocyclohexane, which is much less expensive than chiral trans-1,2-diaminocyclohexane. Because racemic compounds are unsuitable as gelators, as previously mentioned, the development of racemic gelators would represent an important advancement. Gelation tests were performed using an upside-down test-tube method. The macroscopic manifestation of successful gelation is the absence of observable flow when a sample is inverted. The results of the gelation tests with eight solvents are summarized in Table 1. Regarding $(\boldsymbol{R}, \boldsymbol{R})$-C12C12, we have already reported its prominent gelation ability in a previous communication. ${ }^{30}$

Table 1. Results of gelation tests at $25^{\circ} \mathrm{C}$.

\begin{tabular}{|c|c|c|c|c|c|c|}
\hline Solvent & $(R, R)-\mathrm{C} 12 \mathrm{C} 18$ & rac-C12C18 & $(R, R)-\mathrm{C} 5 \mathrm{H} 18$ & rac-C5H18 & $(R, R)-\mathrm{C} 12 \mathrm{C} 12$ & rac-C12C12 \\
\hline Ethyl acetate & GTL(8) & $P$ & GTL(8) & $\mathrm{P}$ & $\mathrm{GO}(8)$ & $\mathrm{GO}(6)^{*}$ \\
\hline Isopropyl myristate & $\operatorname{GTL}(10)$ & GTL(20) & $\operatorname{GTL}(10)$ & GTL(4) & $\operatorname{GTL}(10)$ & $\mathrm{P}$ \\
\hline$\gamma$-Butyrolactone & $\mathrm{P}$ & GT(40) & GTL(8) & GT(20) & $\mathrm{GO}(20)$ & $\mathrm{P}$ \\
\hline Toluene & GT(40) & $\mathrm{GT}(40)$ & GT(40) & GT(20) & GT(12) & GT $(20)^{*}$ \\
\hline Liquid paraffin & $\mathrm{GT}(4)$ & $\operatorname{GTL}(10)$ & GT(4) & GTL(8) & GT(3) & GTL(4) \\
\hline Silicone oil (KF-54) & GTL(8) & GT( $(8)$ & GT(2) & GT(2) & GT(2) & GT(4) \\
\hline D5 & GTL(4) & $\mathrm{GO}(20)$ & $\mathrm{GO}(8)$ & GTL(4) & $\mathrm{GO}(2)$ & $\mathrm{P}$ \\
\hline HDEH & GTL(8) & GTL $(20)$ & $\mathrm{GT}(8)$ & GTL $(8)$ & GTL(4) & GTL $(8)^{*}$ \\
\hline
\end{tabular}

GT: Transparent gel. GTL: Translucent gel. GO: Opaque gel. P: Precipitation. I: Almost insoluble. PG: Partial gel. KF-54: Poly(methylphenylsiloxane) of $400 \mathrm{cS}$. D5: Decamethyl cyclopentasiloxane. HDEH; Hexadecyl 2-ethylhexanoate. The values indicate the minimum gel concentrations at $25^{\circ} \mathrm{C}$; the units are $\mathrm{g} / 1$ (gelator/solvent). ${ }^{*}$ Crystals precipitated from the formed gels after several hours. 
Notably, rac-C12C12 could gel some of the solvents, but the formed gels were so unstable that crystallization occurred after several hours. In general, crystallization of a racemic mixture gives a racemic crystal comprising equivalent $R$ - and $S$-configurations but does not result in precipitation of each chiral crystal separately. The facts that racemic crystals tend to be denser than their chiral counterparts and that complimentarily packing of $R$ - and $S$-configurations gives more high-density crystals is known as Wallach's rule. ${ }^{34,35}$ This rule is the reason that racemic mixtures are unsuitable as gelators.

New gelators $(\boldsymbol{R}, \boldsymbol{R})-\mathbf{C 1 2 C 1 8}$ and $(\boldsymbol{R}, \boldsymbol{R})-\mathbf{C} 5 \mathrm{H18}$ had high gelation abilities comparable to that of $(R, R)$-C12C12. Surprisingly, contrary to Wallach's rule, rac-C12C18 and rac-C5H18 formed very stable gels in isopropyl myristate, $\gamma$-butyrolactone, toluene, liquid paraffin, silicone oil (KF-54), decamethyl cyclopentasiloxane (D5), and hexadecyl 2-ethylhexanoate (HDEH), which were not transformed into crystals. The observation that rac-C12C18 and rac-C5H18 formed more stable gels than rac-C12C12 can be explained on the basis of the disorder of molecular packing. The different substituents in rac-C12C18 and rac-C5H18 prevent the complimentarily denser packing; consequently, rac-C12C18 and rac-C5H18 are not precipitated as racemic crystals. The order of gelation ability to form stable gels is $(\boldsymbol{R}, \boldsymbol{R})-\mathrm{C12C12} \approx$ $(R, R)-\mathrm{C} 12 \mathrm{C} 18 \approx(R, R)-\mathrm{C} 5 \mathrm{H} 18>r a c-\mathrm{C} 12 \mathrm{C} 18 \approx \operatorname{rac}-\mathrm{C} 5 \mathrm{H} 18$ $>$ rac-C12C12.

The gelation abilities of $(R, R)-C 12 C 18,(R, R)-C 5 H 18$, rac-C12C18, and rac-C5H18 were investigated using three-component mixed solvents frequently used in cosmetics: HDEA as a polar oil, liquid paraffin as a non-polar oil, and D5 as a silicone oil. The concentrations of $(R, R)-\mathbf{C 1 2 C 1 8}$, rac-C12C18, $(R, R)-C 5 H 18$, and rac-C5H18 were fixed at 8, 10,8 , and $8 \mathrm{mg} \mathrm{mL}^{-1}$ (gelator/solvent), respectively. The gelation behavior of $(\boldsymbol{R}, \boldsymbol{R})-\mathbf{C 1 2 C 1 8}$ in the mixed solvent (66 combinations, with weight ratios ranging from 10:0:0 to 0:0:10 of HDEH, liquid paraffin, and D5) is shown in Figure 1. We observed that $(\boldsymbol{R}, \boldsymbol{R})-\mathbf{C 1 2 C 1 8}$ formed translucent gels with all these mixed solvent combinations. The same gelation behavior described in Figure 1 was observed for rac-C12C18, $(\boldsymbol{R}$, R)-C5H18, and rac-C5H18

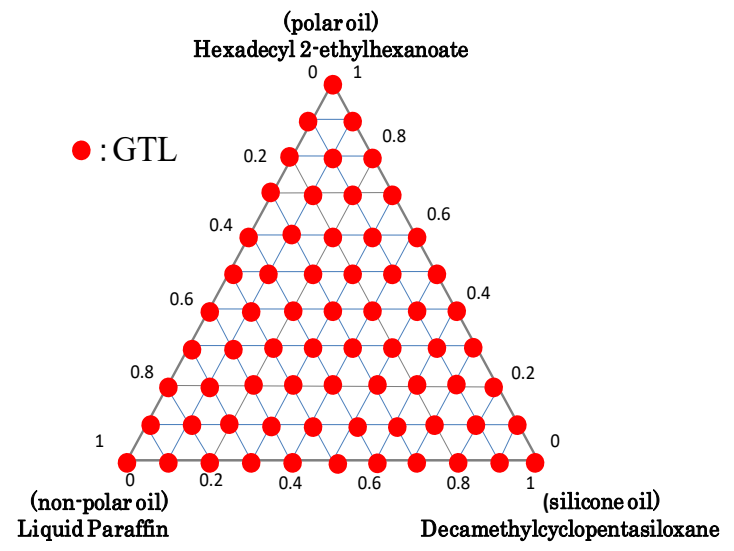

Figure 1. Gelation behavior of $(\boldsymbol{R}, \boldsymbol{R})-\mathbf{C 1 2 C 1 8}$ in the mixed solvent of $\mathrm{HDEH}$, liquid paraffin, and D5 at concentration of $8 \mathrm{mg} \mathrm{mL}^{-1}$.

The phase-transition temperatures of the prepared gels were investigated; the results are shown in Figure 2. As shown in Figure 2A, the greatest thermal stability was observed for gels formed by $(\boldsymbol{R}, \boldsymbol{R})$-C5H18; their gel-to-sol phase-transition temperatures were within 95 to $115^{\circ} \mathrm{C}$. The second-most thermally stable gels were formed by $\mathbf{r a c}-\mathbf{C 5 H 1 8}$, as shown in
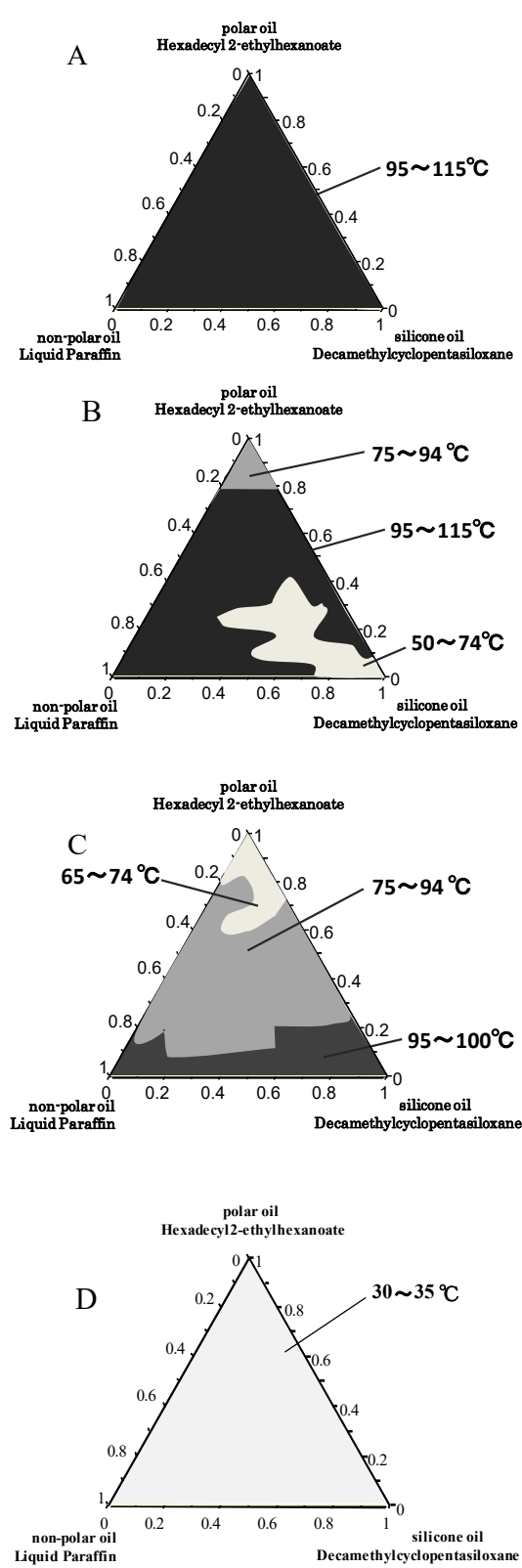

Figure 2. Gel-to-sol phase-transition temperatures in the mixed solvent of $\mathrm{HDEH}$, liquid paraffin, and D5 at concentration of $8 \mathrm{mg} \mathrm{mL}^{-1}$ : (A) (R, R)-C5C18, (B) rac-C5C18, (C) $(R, R)-C 12 C 18$, and (D) rac-C12C18.

Figure 2B. In the case of $(\boldsymbol{R}, \boldsymbol{R})-\mathbf{C 1 2 C 1 8}$, when the content of HDED (polar oil) in the mixed solvents was increased, the phase-transition temperature which decreased from $65^{\circ} \mathrm{C}$ to $74^{\circ} \mathrm{C}$ was shown in Figure 2C. Figure 2D showed that the lowest phase-transition temperatures were observed in the gels formed by $r a c-C 12 C 18$. The high phase-transition temperatures of $(\boldsymbol{R}, \boldsymbol{R})$-C5H18 and rac-C5H18 compared to those of $(\boldsymbol{R}, \boldsymbol{R})-\mathbf{C 1 2 C 1 8}$ and rac-C12C18 is explained by the hydrogen bonding among hydroxyl groups. Although the reason of the low phase-transition temperatures of rac-C12C18 compared to those of $(\boldsymbol{R}, \boldsymbol{R})-\mathbf{C 1 2 C 1 8}$ remains unclear, the enantiomer may prevent aggregate growth.

Transparent gels are widely desirable from a practical application perspective. We used UV-vis spectroscopy to evaluate the transparency of the prepared gels. As shown in Figure S1 the six gelators investigated in this work formed transparent or translucent gels. The transmittance spectra of 
gels composed of a mixture of HDEH, liquid paraffin, and D5 (vol. ratio 4:3:3) are shown in Figure 3. The transmittances at $400 \mathrm{~nm}$ of gels of $(\boldsymbol{R}, \boldsymbol{R})-\mathrm{C12C18},(\boldsymbol{R}, \boldsymbol{R})-\mathrm{C12C12},(\boldsymbol{R}$, $R)-C 5 H 18, r a c-C 12 C 18, r a c-C 12 C 12$, and rac-C5C18 at a concentration of $10 \mathrm{mg} \mathrm{mL}^{-1}$ were $94,79,95,58,79$, and $82 \%$, respectively. The order of transparency of gels over the total investigated wavelength band is $(\boldsymbol{R}, \boldsymbol{R})-\mathrm{C12C18} \approx(\boldsymbol{R}$, $R)-\mathrm{C} 5 \mathrm{H} 18>(R, R)-\mathrm{C} 12 \mathrm{C} 12 \approx \operatorname{rac}-\mathrm{C} 5 \mathrm{H} 18>\operatorname{rac}-\mathrm{C} 12 \mathrm{C} 18 \approx$ rac-C12C12. The transmittance of the rac-C12C12 gel rapidly decreased because the gel crystallized. The transparency of gels is thought to depend on the size of the aggregates constructing the three-dimensional networks responsible for physical gelation. When the width of the aggregates becomes equivalent to the wavelength of visible light, the formed gels will be opaque because they will scatter visible light. Because the disordered arrangements of structurally different substituents in $(R, R)$-C12C18 and $(R, R)$-C5H18 form aggregates with random molecular packing, the aggregates cannot grow to a size comparable to the wavelength of visible light. The different substituents in these compounds are thought to disturb the molecular packing. The introduction of structurally different substituents will be useful for developing gelators to form transparent gels.

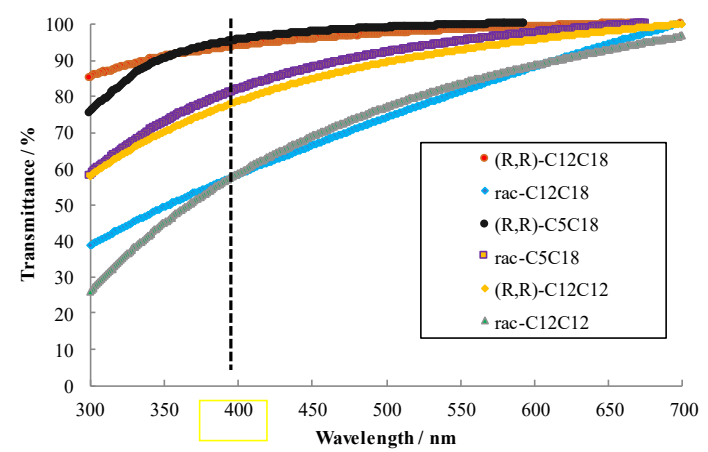

Figure 3. Transmittance change of gels at $10 \mathrm{mg} \mathrm{mL}^{-1}$ in the mixture of polar oil:non-polar oil:silicone oil $=4: 3: 3$, as measured using a UV-vis spectrophotometer.

\subsection{Rheology}

As shown in Figure S2 - S4, the viscoelastic behavior of the gels was studied by rheology measurements in strain sweep mode and frequency sweep mode at $25^{\circ} \mathrm{C}$. The solvent used for the measurements was a mixture of $\mathrm{HDEH}$, liquid paraffin, and D5 (vol. ratio 4:3:3) and the concentrations were $10 \mathrm{mg} \mathrm{mL}^{-1}$. In strain sweep mode at $0.03 \mathrm{~Hz}$, the storage elastic moduli $\left(G^{\prime}\right)$ of almost all of the investigated gels were larger than the loss elastic moduli $\left(G^{\prime \prime}\right)$ up to a strain of 0.1 and the $G^{\prime \prime}$ of the gels exceeded the $G^{\prime}$ at a strain of 0.5 , which demonstrates the collapse of gels. In frequency sweep mode at a strain of 0.2 , plateau regions of $G^{\prime}$ and $G^{\prime \prime}$ of all the samples were observed up to $1 \mathrm{~Hz}$, where the $G^{\prime}$ exceeded the $G^{\prime \prime}$. In particular, the $G^{\prime}$ of $(R, R)-\mathbf{C 1 2 C 1 8},(R, R)-\mathbf{C} 5 \mathrm{H} 18$, and rac-C5H18 exceeded the $G^{\prime \prime}$ up to $5 \mathrm{~Hz}$. Average $G^{\prime}$ and $G^{\prime \prime}$ in the plateau regions of 0.002 to $1.0 \mathrm{~Hz}$, referred to as $G_{\text {Ave' }}$ and $G_{\text {Ave }}$ ", and loss angle $\tan \delta_{\text {Ave }}$ are summarized in Table 2, where the tangent of the phase angle $\left(\tan \delta_{\text {Ave }}\right)$-the ratio of $G_{\text {Ave }}$ " to $G_{\text {Ave }}$ ' is a useful quantifier of the presence and extent of elasticity in a gel system. $^{39-41}$ The $\tan \delta_{\text {Ave }}$ values of less than unity indicate elastic-dominant behavior and values greater than unity indicate viscous-dominant behavior. Regarding chiral compounds, the order of $G_{\mathrm{Ave}}{ }^{\prime}$ is $(\boldsymbol{R}, \boldsymbol{R})-\mathbf{C 1 2 C 1 2}<(\boldsymbol{R}$, $\boldsymbol{R})-\mathrm{C} 12 \mathrm{C} 18<(\boldsymbol{R}, \boldsymbol{R})-\mathrm{C5C} 18$ and that of $\tan \delta_{\text {Ave }}$ is $(\boldsymbol{R}$,
Table 2. $G_{\text {Ave }}$ ', $G_{\text {Ave }}$, and $\tan \delta_{\text {Ave }}$ under a strain of 0.02 at $25^{\circ} \mathrm{C}$.

\begin{tabular}{lccl}
\hline & $G_{\text {Ave }}{ }^{\prime}(\mathrm{Pa})$ & $G_{\text {Ave }}{ }^{\prime}(\mathrm{Pa})$ & $\tan \delta_{\text {Ave }}$ \\
\hline$(\boldsymbol{R}, \boldsymbol{R})-\mathbf{C 1 2 C 1 8}$ & 1455 & 303 & 0.20 \\
$\boldsymbol{r a c}-\mathbf{C 1 2 C 1 8}$ & 488 & 83 & 0.18 \\
$(\boldsymbol{R}, \boldsymbol{R})-\mathbf{C 5 C 1 8}$ & 2507 & 681 & 0.33 \\
$\boldsymbol{r a c}-\mathbf{C 5 C 1 1}$ & 1467 & 442 & 0.36 \\
$(\boldsymbol{R}, \boldsymbol{R})-\mathbf{C 1 2 C 1 2}$ & 1150 & 456 & 0.45 \\
$\boldsymbol{r a c - C 1 2 C 1 2}$ & 857 & 291 & 0.38 \\
\hline
\end{tabular}

$R)-\mathrm{C} 12 \mathrm{C} 12>(R, R)-\mathrm{C} 5 \mathrm{C} 18>(R, R)-\mathrm{C} 12 \mathrm{C} 18$. Namely, $(R$, $R)$-C5C18 and $(R, R)$-C12H18 with different substituents could form the harder gels. The hardness of gels seems to depend on size and density of aggregate; namely, the fibers consisting of the racemates are thicker than those of the enantiomers. For example, $(\boldsymbol{R}, \boldsymbol{R})$-C12C18 formed fine thread-like aggregates with nearly homogeneous diameters of $\sim 26 \mathrm{~nm}$, whereas the widths of fibers in rac-C12C18 ranged from 42 to $50 \mathrm{~nm}$. Results in SAXS stated later also suggests an importance of substituents; $(\boldsymbol{R}, \boldsymbol{R})-\mathbf{C 1 2 C 1 2}$ and rac-C12C12 with the same substituent formed denser packed aggregates than $(\boldsymbol{R}, \boldsymbol{R})$-C12C18 and rac-C12C18 with the different substituent. Because $(\boldsymbol{R}, \boldsymbol{R})$-C12C18 and $(\boldsymbol{R}, \boldsymbol{R})$-C5H18 with different substituents form fine aggregates, consequently, $3 \mathrm{D}$ networks in gels are crowded, and finally the hard gels are formed. The large $G_{\text {Ave' }}$ of $(\boldsymbol{R}, \boldsymbol{R})$-C5H18, compared to those of $(\boldsymbol{R}, \boldsymbol{R})-\mathbf{C 1 2 H 1 8}$, will be attributed to the participation of hydrogen bonding among hydroxyl groups.

Next, we compared the behavior of the racemates; rac-C12C12, rac-C12C18, and rac-C5H18. Their behavior of $G_{\text {Ave }}$ is almost similar to that of chiral, i.e., the order of $G_{\text {Ave' }}$ is rac- $\mathbf{C 5 C 1 8}>$ rac-C12C12 > rac-C12C18. $G_{\mathrm{Ave}}{ }^{\prime}$ and $G_{\mathrm{Ave}}{ }^{\prime \prime}$, and $\tan \delta_{\text {Ave }}$ of rac-C5C18 were $1467 \mathrm{~Pa}, 442 \mathrm{~Pa}$, and 0.36 respectively. Meanwhile, those of $(\boldsymbol{R}, \boldsymbol{R})$-C5H18 were $2507 \mathrm{~Pa}$, $681 \mathrm{~Pa}$, and 0.33 , respectively. These results indicate that the gel strength of rac-C5C18 was comparable to that of $(\boldsymbol{R}$, $R)$-C5C18. The large $G_{\text {Ave' }}$ of $(R, R)-C 5 H 18$ and rac-C5H18 suggests that the hydrogen bonding among hydroxyl groups plays an important role in gelation.

3.3. TEM

The transparency and rheology behavior of the formed gels depended on the substituents and chirality of the gelators. Aggregates that formed three-dimensional networks consisting of gelator molecules were observed by TEM. Figure 4 shows TEM images of loose gels formed by $(\boldsymbol{R}, \boldsymbol{R})$-C12C18, rac-C12C18, $(R, R)-\mathrm{C} 5 \mathrm{C} 18$, rac-C5C18, $(R, R)-\mathrm{C12C12}$, and rac-C12C12. The solvent was a mixture of $\mathrm{HDEH}$, liquid paraffin, and D5 (vol. ratio 4:3:3). The concentrations of gelators for preparing samples were $0.5 \mathrm{mg} \mathrm{mL}^{-1}$ for $(\boldsymbol{R}$, $R)-C 12 C 18$, rac-C12C18, $(R, R)-C 5 C 18$, and rac-C5C18 and $0.8 \mathrm{mg} \mathrm{mL}^{-1}$ for $(\boldsymbol{R}, \boldsymbol{R})-\mathbf{C 1 2 C 1 2}$ and rac-C12C12. Because the concentrations of gelators used to prepare TEM samples were considerably lower than the minimum gel concentrations, the images in Figure 4 show fibers consisting of loose gels before actual gelation. The image of $(\boldsymbol{R}, \boldsymbol{R})$-C12C18 shows fine thread-like aggregates with nearly homogeneous diameters of $\sim 26 \mathrm{~nm}$. By contrast, the widths of fibers in rac-C12C18 ranged from 42 to $50 \mathrm{~nm}$, which is larger than the widths of the fibers in $(\boldsymbol{R}, \boldsymbol{R})$-C12C18. The transparent gels formed by $(\boldsymbol{R}$, $R)-\mathbf{C 1 2 C 1 8}$ may be a consequence of the fine fibers. The widths of fibers of $(\boldsymbol{R}, \boldsymbol{R})$-C5C18 and rac-C5C18 were $\sim 20 \mathrm{~nm}$ and $30-58 \mathrm{~nm}$, respectively. The fibers formed by the racemates are thicker than those formed by the enantiomers. The helicity of fibers of $(\boldsymbol{R}, \boldsymbol{R})-\mathbf{C 1 2 C 1 2}$ in acetonitrile was left-handed, as reported previously. ${ }^{42}$ As shown in Figure S5, 
FE-SEM images also confirmed the left-handed helicity in the gels of toluene and isopropyl myristate. For reasons not clear to us, Figure 4A showed helical aggregates were not observed in gels formed by $(\boldsymbol{R}, \boldsymbol{R})$-C12C18. The fibers of $(\boldsymbol{R}, \boldsymbol{R})-\mathbf{C 1 2 C 1 8}$ are so thin that they did not grow into helical aggregates that could be observed by TEM. Notably, as shown in Figure 4F, helical aggregates were observed in gels formed by rac-C12C12, although the helicity was unclear. We reasonably assume that the $(\boldsymbol{R}, \boldsymbol{R})-\mathbf{C 1 2 C 1 2}$ and trans- $(1 S, 2 S)$ 1,2-bis(dodecanoylamino)cyclohexane of the enantiomer included in rac-C12C12 form helical fibers individually in the gel. However, this gel was unstable and crystallized via reconstitution of the enantiomers because of Wallach's rule.

To confirm the helical aggregates of $(\boldsymbol{R}, \boldsymbol{R})$-C12C18, which we failed to detect in TEM and FE-SEM images, we recorded the gel's CD spectra. The solvent for CD spectroscopy was a mixture of $\mathrm{HDEH}$, liquid paraffin, and D5 (vol. ratio; 4:3:3), and the concentration of $(\boldsymbol{R}, \boldsymbol{R})-\mathbf{C 1 2 C 1 8}$ in the prepared samples was $8 \mathrm{mg} \mathrm{mL}^{-1}$. The CD spectrum of $(\boldsymbol{R}, \boldsymbol{R})-\mathbf{C 1 2 C 1 8}$ at $25^{\circ} \mathrm{C}$ exhibited markedly strong peak for the amide unit: $[\theta]_{210}=\sim 50 \mathrm{mdeg}$. The intensity of this peak decreased with increasing temperature and disappeared at $50^{\circ} \mathrm{C}$ because the loose gel was transformed into an isotropic solution. The disappearance of the CD signal in the isotropic solution led us to conclude that the strong $\mathrm{CD}$ band originates from helical aggregates of $(\boldsymbol{R}, \boldsymbol{R})-\mathbf{C 1 2 C 1 8}$ and not from the chirality of $(\boldsymbol{R}$, $\boldsymbol{R})$-C12C18 itself. The strong CD band supports the existence of helical aggregates in the gels of $(R, R)-C 12 C 18$.

\subsection{SAXS}
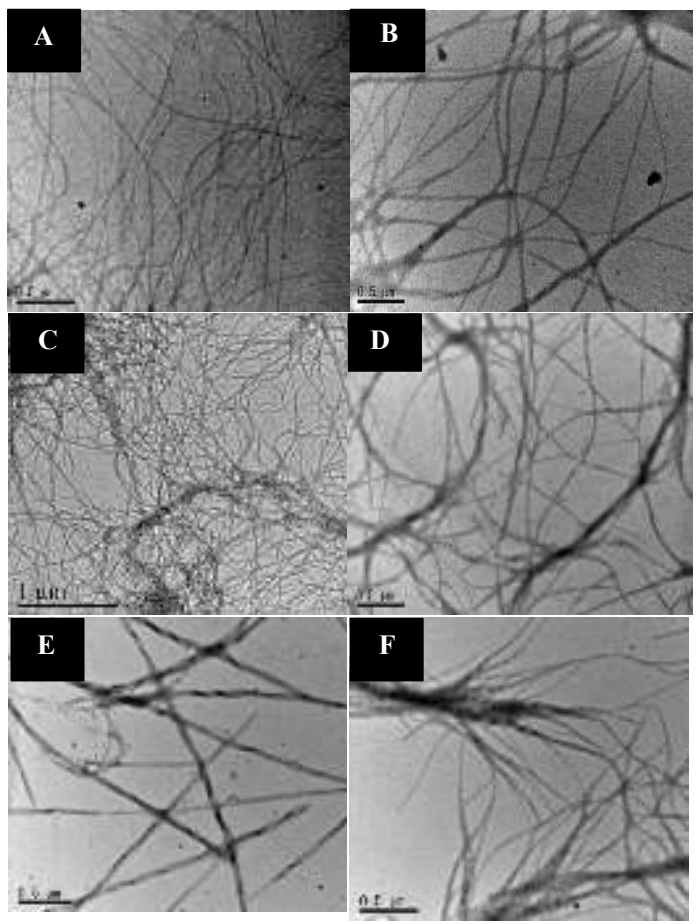

Figure 4. TEM images of gels prepared from (A) ( $\boldsymbol{R}$, R)-C12C18 (0.5 mg mL $\left.\mathrm{mL}^{-1}\right)$, (B) rac-C12C18 (0.5 $\mathrm{mg}$ $\left.\mathrm{mL}^{-1}\right),(\mathrm{C})(\boldsymbol{R}, \boldsymbol{R})-\mathbf{C} \mathbf{C} 18\left(0.5 \mathrm{mg} \mathrm{mL}^{-1}\right)$, (D) rac-C5C18 $\left(0.5 \mathrm{mg} \mathrm{mL}^{-1}\right),(\mathrm{E})(\boldsymbol{R}, \boldsymbol{R})-\mathbf{C 1 2 C 1 2}\left(0.8 \mathrm{mg} \mathrm{mL}^{-1}\right)$, and (F) rac-C12C12 $\left(0.8 \mathrm{mg} \mathrm{mL}^{-1}\right)$ in a mixture of polar oil:non-polar oil:silicone oil $=4: 3: 3$.

The TEM observations suggested that the size and shape of aggregates in the gels depended on the type of substituents and the chirality of the gelators. To study the static structure of the aggregates in detail, we employed SAXS analyses. Figure 5 shows the SAXS intensities, $I(q)$, of dilute gel samples prepared from $(R, R)-\mathbf{C 1 2 C 1 8}, \operatorname{rac}-\mathbf{C 1 2 C 1 8},(R, R)-\mathrm{C12C12}$, and $\mathrm{rac}-\mathrm{C12C12}$ at $25^{\circ} \mathrm{C}$ on an absolute scale, where the solvent was HDEH and the concentration of the gelator was 10 $\mathrm{mg} \mathrm{mL}{ }^{-1}$. The forward intensities of $(\boldsymbol{R}, \boldsymbol{R})-\mathbf{C 1 2 C 1 2}$ and rac-C12C12 were significantly greater than those of rac-C12C18 and $(R, R)-C 12 C 18$, demonstrating that $(R$, $R)-C 12 C 12$ and rac-C12C12 formed larger aggregates. We infer that $(\boldsymbol{R}, \boldsymbol{R})-\mathrm{C12C12}$ and rac-C12C12 form more densely packed aggregates than $(R, R)-C 12 C 18$ and rac-C12C18. The denser packing of $(R, R)-\mathbf{C 1 2 C 1 2}$ and rac-C12C12 appears to be a consequence of their ordered compact structures, because these gelators have the same substituents in their molecules, i.e., two $n$-dodecanoyl groups.

We next conducted a concentration series of SAXS

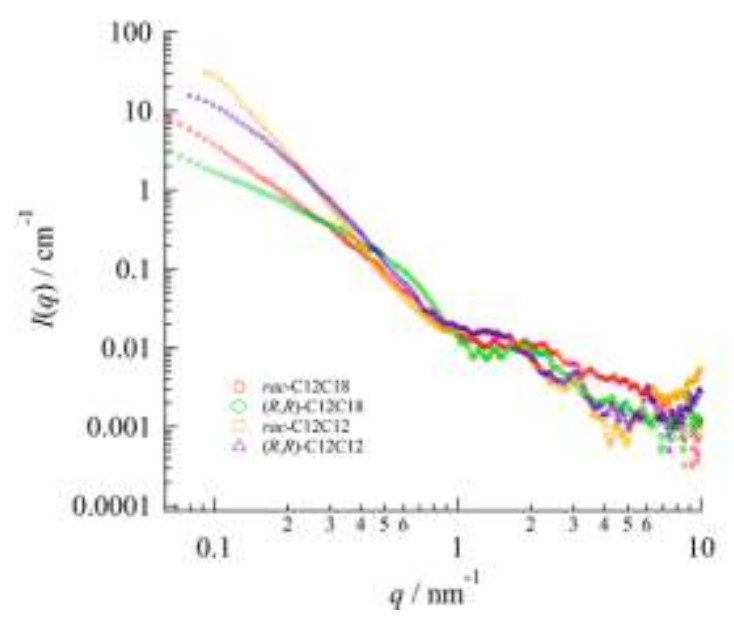

Figure 5. SAXS intensities, $I(q)$, of the gels prepared from rac-C12C18, $(R, R)-\mathrm{C12C18}, \quad$ rac-C12C12, and $(R$, R)-C12C12 at $10 \mathrm{mg} \mathrm{mL}^{-1}$ at $25^{\circ} \mathrm{C}$ on an absolute scale. HDEH was used as the solvent.
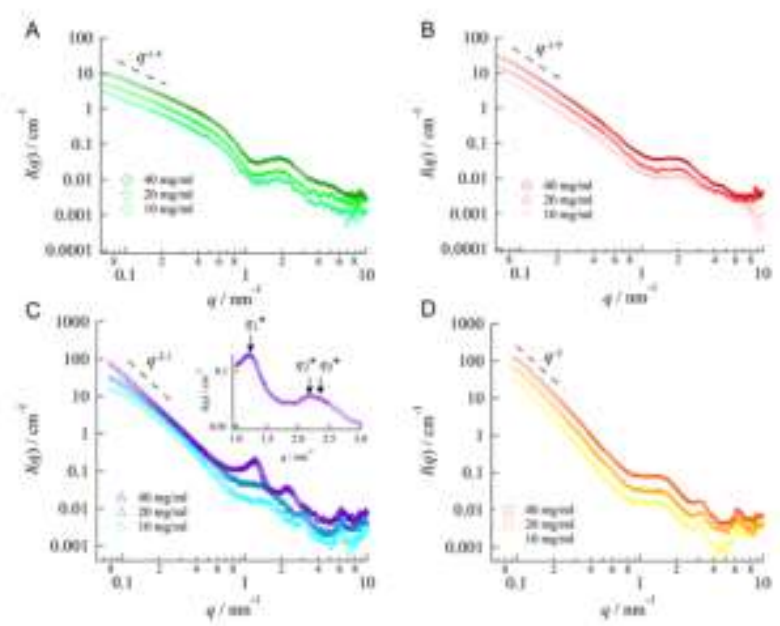

Figure 6. Concentration-dependence of the SAXS intensities $I(q)$ of gels at $25^{\circ} \mathrm{C}$ in $\mathrm{HDEH}$ on an absolute scale. A; $(R, R)-C 12 C 18, B ; r a c-C 12 C 18, C ; \quad(R$, $R)-C 12 C 12$, D; rac-C12C18.

experiments, and the results are demonstrated in Figure 6 . Comparison of the $I(q)$ values of rac-C12C12 and $(\boldsymbol{R}$, $\boldsymbol{R})$-C12C12 in the region $0.1<q / \mathrm{nm}^{-1}<1$ reveals that the $I(q)$ of rac-C12C12 is nearly proportional to $q^{-3}$, regardless of the concentration. The greater forward intensities and the steeper slope of rac-C12C12 compared to those of other systems 
demonstrated that this system forms larger aggregates than the other compounds. Because rac-C12C12 has identical substituents in its molecules, it can easily achieve denser packing compared to other compounds with different substituents. In fact, rac-C12C12, comprising both the $R$ - and $S$-configurations, tended to form high-density crystals due to Wallach's rule. The $q^{-4}$ behavior is generally called the Porod scattering and is ascribed to interface formation. At low concentrations, such as 10 and $20 \mathrm{mg} \mathrm{mL}^{-1}$, the slope of the $I(q)$ of $(\boldsymbol{R}, \boldsymbol{R})-\mathbf{C 1 2 C 1 2}$ in the forward direction was still gentler than $q^{-4}$, indicating that, even at $40 \mathrm{mg} \mathrm{mL}^{-1}$, the aggregation tendency of the gelator was not strong enough to form a well-defined interface between the solvent and the fiber bundle-like higher-order aggregates.

The slope of the $I(q)$ of $(\boldsymbol{R}, \boldsymbol{R})$-C12C18 and rac-C12C18 in the region $0.1<q / \mathrm{nm}^{-1}<1$ was virtually independent of the concentration. Generally, the fractal dimension of the scattering object, $d_{\mathrm{f}}$, is manifested in the asymptotic exponent as $I(q) \propto q^{-}$ ${ }^{d \mathrm{f}}$. 43 The asymptotic behavior of $I(q) \propto q^{-1}$ and $I(q) \propto q^{-2}$ in the forward direction can be assigned to rod and planar structures, respectively. As for $(\boldsymbol{R}, \boldsymbol{R})$-C12C18, we observed a slope of $q^{-1.4}$ for $q<0.3 \mathrm{~nm}^{-1}$ instead of $q^{-1}$, which implied the formation of aggregating rods. A steeper slope of $q^{-1.9}$ was observed for $\boldsymbol{r a c}-\mathbf{C 1 2 C 1 8}$, which was still slightly gentler than but close to $q^{-2}$, which may be assigned to a planar-like structure or alternatively an aggregating rod structure. If the gelling systems at low gelator concentrations can be regarded as a dilute dispersion of colloidal particles, $I(q)$ may be interpreted as the Fourier transformation of the pair-distance distribution function, $p(r)$, as given by

$$
I(q)=4 \pi \int_{0}^{\infty} p(r) \frac{\sin q r}{q r} \mathrm{~d} r \quad(1)^{44,45}
$$

To obtain $p(r)$ corresponding to the structure function in real space, we performed Fourier inversion analyses of the SAXS intensities $I(q)$ of $(\boldsymbol{R}, \boldsymbol{R})-\mathbf{C 1 2 C 1 8}$ and rac-C12C18 at $40 \mathrm{mg}$ $\mathrm{mL}^{-1}$. First, we used an indirect Fourier transformation (IFT) technique, ${ }^{46,47}$ assuming an isotropic dilute dispersion. The IFT fits to the experimental $I(q)$ and the resulting $p(r)$ values are displayed in Figure 7. As shown in Figure 7B, the deduced $p(r)$ of $(\boldsymbol{R}, \boldsymbol{R})$-C12C18 exhibits typical features of a rod-like structure, namely a local maximum in the low- $r$ regime and an extended tail in the high- $r$ regime. The maximum length, exceeding $50 \mathrm{~nm}$, and the cross-sectional diameter, about $6 \mathrm{~nm}$, can be determined from the maximum distance, where $p(r)$ approaches zero and the infraction point of $p(r)$ is seen on the slightly higher- $r$ side of the local maximum. The latter is highlighted by an arrow and a dotted line in Figure 7B. Importantly, we simultaneously observed the emergence of a second additional local maximum at $r \approx 13 \mathrm{~nm}$, as indicated by a dotted arrow. Note that this behavior is quite similar to that observed for the $p(r)$ of the aggregating rod-like normal and reverse micelles in aqueous ${ }^{48}$ as well as lipophilic ${ }^{49}$ solvent conditions. The rac-C12C18 system showed a more pronounced second local maximum, which is overwhelming and appears to hinder the first local maximum. Strongly linked with the $q^{-1.9}$ slope of the forward intensity, the $p(r)$ of rac-C12C18, at a glance, resembles that of a planar structure, rather than that of a rod structure. However, we point out that the aggregating rods, closely positioned with a small mutual tilt angle, say less than $30^{\circ}$, can mimic the $p(r)$ of a planar-like structure; see Figure 8 or the literature. ${ }^{43}$

We tried to further confirm the above-mentioned IFT results and verify the aggregating rod-like structures in a more
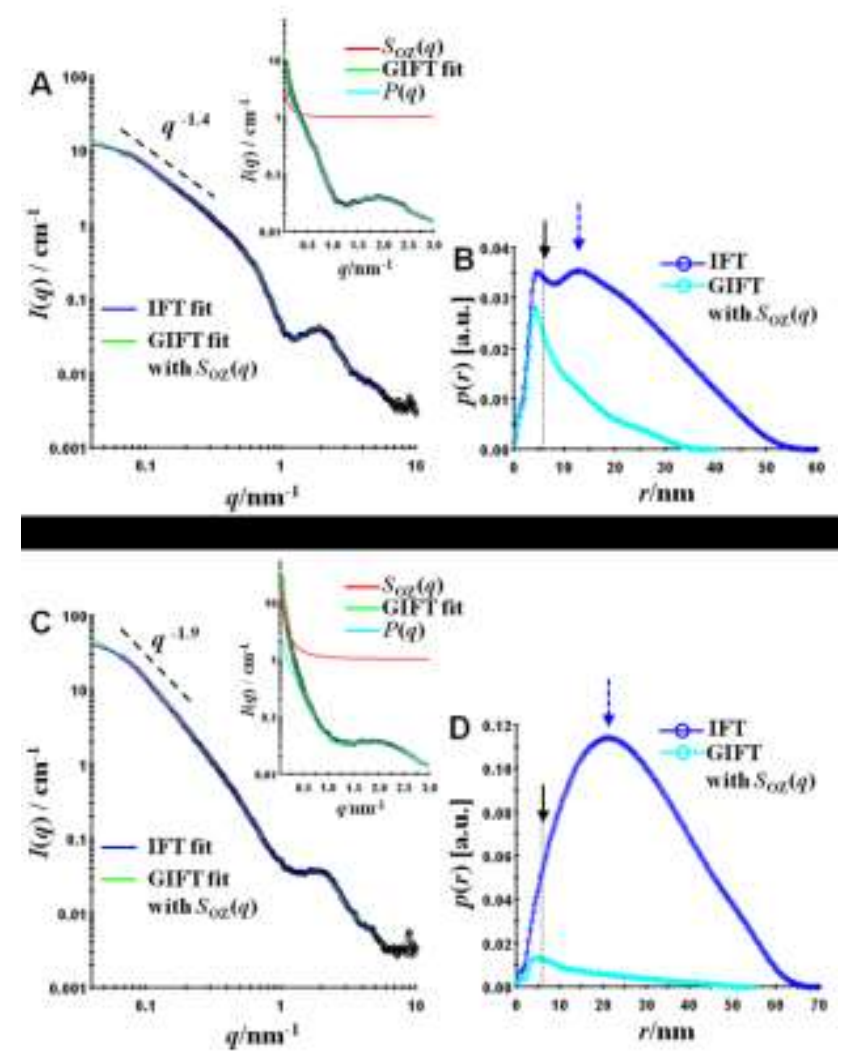

Figure 7. Fourier inversion analyses of SAXS intensities of $(\boldsymbol{R}, \boldsymbol{R})-\mathbf{C 1 2 C 1 8}$ (A and B) and rac-C12C18 (C and D) gels (40 $\mathrm{mg} \mathrm{mL}^{-1}$ ) at $25^{\circ} \mathrm{C}$ using IFT/GIFT technique. The IFT and GIFT fit results respectively without and with the Ornstein-Zernike structure factor model (A and $\mathrm{C}$ ) and the resulting pair-distance distribution functions, $p(r)(\mathrm{B}$ and $\mathrm{D})$.

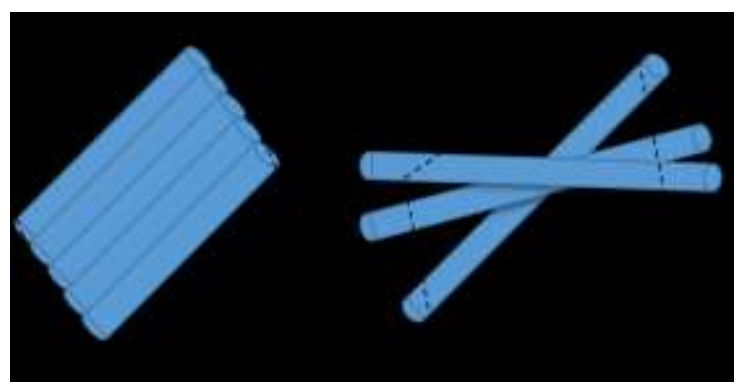

Figure 8. Schematic diagram of two structures discussed about rac-C12C18. Planer structure (left) and planer-like aggregates by aggregated-rods (right).

quantitative manner. An alternative interpretation of the enhanced forward scattering, i.e., $I(q) \propto q^{-1.4}$ for $(\boldsymbol{R}$, R)-C12C18 and $I(q) \propto q^{-1.9}$ for rac-C12C18, could be a critical-like concentration fluctuation due to the attractive interaction between the rod-like aggregates and the resulting upturn increase of the structure factor in the low- $q$ region $(S(q)$ $>1)$. We used a generalized indirect Fourier transformation (GIFT) technique, ${ }^{50,51}$ taking the local concentration fluctuations into account. For the gel systems, we assumed a relation describing a concentrated colloidal dispersion, $I(q)=$ $n P(q) \operatorname{Soz}(q)$, where $P(q)$ is the form factor of the primary rod-like aggregates and $S_{\mathrm{Oz}}(q)$ is a modified Ornstein-Zernike 
(OZ) structure factor, in which $\operatorname{Soz}(q)$ is approximated by a Lorentzian function:

$$
S_{\mathrm{OZ}}(q)=1+\frac{n k_{\mathrm{B}} T \chi_{\mathrm{T}}}{1+q^{2} \xi^{2}}
$$

where $k_{\mathrm{B}}$ is the Boltzmann constant, $T$ is the absolute temperature, $\xi$ is the correlation length describing the length scale of the local concentration fluctuations, $n$ is the particle number density, and $\chi_{\mathrm{T}}$ is the isothermal osmotic compressibility. We treated $\xi$ and the amplitude, $n k_{\mathrm{B}} T \chi_{\mathrm{T}}$, as the variable parameters, which grow when approaching the

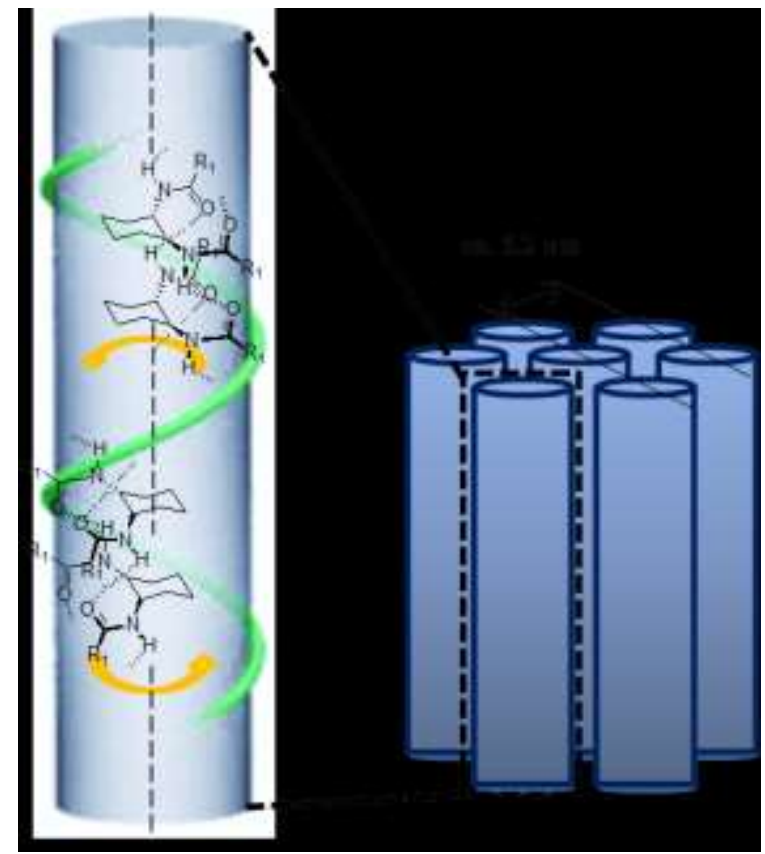

Figure 9. Organogel structure of $(R, R)-\mathrm{C} 12 \mathrm{C} 12$ with higher-order aggregates formed in hexadecyl 2-ethylhexanoate.
$R$ - and $S$-configurations in rac-C12C18 gives more high-density crystals, according to Wallach's rule. The IFT/GIFT results for these two gel systems led us to conclude that the presence of a long rod-like or strand structure is most likely and that these were aggregated to some extent in an aligned manner, but did not form a crystalline-like structure.

As we already discussed, neither a change in the position of the local maximum, nor a change in the slope of $I(q)$ was observed for $(\boldsymbol{R}, \boldsymbol{R})-\mathrm{C12C18}$ and $\boldsymbol{r a c}-\mathrm{C12C18}$ with increasing concentration, as shown in Figure 7A and 7B. By contrast, with increasing concentration of $(R, R)-\mathrm{C} 12 \mathrm{C12}$ and rac-C12C12, an interference peak $\left(q_{\mathrm{h}}\right)$ at about $6 \mathrm{~nm}^{-1}$ appeared, corresponding to a $d$-spacing of $\sim 1 \mathrm{~nm}$ if Bragg's law was applied to $q_{\mathrm{h}}$. Judging from the fact that the $q_{\mathrm{h}} \approx 6 \mathrm{~nm}^{-1}$ condition did not change with concentration, the peak appears to be attributed to the short distance between gelator molecules within the aggregates. Broad peaks of $(\boldsymbol{R}, \boldsymbol{R})-\mathbf{C 1 2 C 1 2}$ and rac-C12C12 in the region $1<q / \mathrm{nm}^{-1}<5$ are derived from the internal structure of the primary aggregates, which are likely to have a rod-like structure, thus do not exhibit inter-aggregate interference scattering. Similar broad peaks of $(\boldsymbol{R}, \boldsymbol{R})$-C12C18 and $r a c-C 12 C 18$ observed in the region $1<q / \mathrm{nm}^{-1}<4$ are also ascribed to the intra-aggregate interference contributions. However, when the concentration of $(\boldsymbol{R}, \boldsymbol{R})-\mathbf{C 1 2 C 1 2}$ was increased to $40 \mathrm{mg} \mathrm{mL}^{-1}$, sharp interference peaks suddenly appeared in the region $0.9<q / \mathrm{nm}^{-1}<4$, as shown in Figure 7C, which are likely to be interference peaks arising from the crystalline-like positional correlations of the aggregates. The interlayer spacing, $d$, values for $(\boldsymbol{R}, \boldsymbol{R})-\mathbf{C 1 2 C 1 2}$ and $r a c-C 12 C 12$, calculated from the interference peak positions, are summarized in Table 3. As previously mentioned, only in the case of $(\boldsymbol{R}, \boldsymbol{R})-\mathbf{C 1 2 C 1 2}$, the forward intensity approached Porod scattering, and sharp peaks suddenly appeared at $40 \mathrm{mg}$ $\mathrm{mL}^{-1}$, which we call the scattering vectors corresponding to the peak positions $q_{1}{ }^{*}$ and $q_{2}{ }^{*}$ from the lower $q$-side. As shown in Figure $7 \mathrm{C}$, the third reflection $\left(q_{3}{ }^{*}\right)$ could also be vaguely identified. Since the positional ratio $q_{1}{ }^{*}: q_{2}{ }^{*}: q{ }^{*}$ was nearly $1: \sqrt{3}: \sqrt{4}$, the packing of the aggregates of $(\boldsymbol{R}, \boldsymbol{R})-\mathbf{C 1 2 C 1 2}$ at 40

Table 3. SAXS diffraction peak data ${ }^{a}$.

\begin{tabular}{llllllll}
\hline Compound & $q_{1}{ }^{*}\left(\mathrm{~nm}^{-1}\right)$ & $q_{2}{ }^{*}\left(\mathrm{~nm}^{-1}\right)$ & $q_{3}{ }^{*}\left(\mathrm{~nm}^{-1}\right)$ & $q_{\mathrm{h}}\left(\mathrm{nm}^{-1}\right)$ & $q_{1}{ }^{*}: q_{2}{ }^{*}: q_{3}{ }^{*}$ & $d_{1}(\mathrm{~nm})$ & $d_{\mathrm{h}}(\mathrm{nm})$ \\
\hline$(\boldsymbol{R}, \boldsymbol{R})-\mathbf{C 1 2 C 1 2}$ & 1.21 & 2.20 & 2.41 & 6.17 & $1: \sqrt{ } 3: \sqrt{4}$ & 5.19 & 1.02 \\
$\boldsymbol{r a c - C 1 2 C 1 2}$ & - & - & - & 6.00 & - & - & 1.05
\end{tabular}

a) The scattering vectors corresponding to the position of the characteristic reflections $q_{n}{ }^{*}(n=1,2, \cdots)$ and the interlayer spac determined from the SAXS intensities. The interlayer spacing $d$ is calculated using Bragg's law, $d_{\mathrm{n}}=2 \pi / q_{\mathrm{n}}{ }^{*}$.

critical point. ${ }^{52,53}$ In general, the $\mathrm{OZ}$ structure factor model is applied to the description of a temperature-induced critical fluctuation. ${ }^{43}$ In this study, we used the same model for the gelling systems in an extended manner. As shown in Figure 7, the GIFT results demonstrated that the experimental $I(q)$ can be excellently reproduced by the product of $P(q)$, having the overall shape of the rod-like particles and $\operatorname{Soz}(q)$ with the optimized parameters, yielding typical shapes of $p(r)$ for the long rod structure, having a cross-sectional diameter of about 6 $\mathrm{nm}$ for both $(\boldsymbol{R}, \boldsymbol{R})$-C12C18 and rac-C12C18. We obtained $\xi$ $=8 \mathrm{~nm}$ and $n k_{\mathrm{B}} T \chi_{\mathrm{T}}=2$ for $(\boldsymbol{R}, \boldsymbol{R})-\mathbf{C 1 2 C 1 8}$ and $\xi=25 \mathrm{~nm}$ and $n k_{\mathrm{B}} T \chi_{\mathrm{T}}=5$ for rac-C12C18, indicating a larger concentration fluctuation for $r a c-C 12 C 18$. The difference in structural morphogenesis between $(\boldsymbol{R}, \boldsymbol{R})$-C12C18 and rac-C12C18 can be explained by the existence of equimolar $(S$, $S)-\mathrm{C12C18}$ in rac-C12C18. The complimentarily packing of $\mathrm{mg} \mathrm{mL}-1$ can be assigned to a hexagonal structure. ${ }^{54}$ As shown in Figure 9, we can conclude that $(\boldsymbol{R}, \boldsymbol{R})$-C12C12 formed rod-like aggregates at low concentrations of 10 and $20 \mathrm{mg} \mathrm{mL}^{-1}$, which then transformed into hexagonal aggregates at $40 \mathrm{mg}$ $\mathrm{mL}^{-1}$.

From the results showing that the forward scattering intensities of $(\boldsymbol{R}, \boldsymbol{R})$-C12C18 and rac-C12C18 are smaller than those of $(\boldsymbol{R}, \boldsymbol{R})-\mathbf{C 1 2 C 1 2}$ and rac-C12C12, and moreover, the absence of interference peaks in $(\boldsymbol{R}, \boldsymbol{R})$-C12C18 and rac-C12C18, we can conclude that the different substituents in $(\boldsymbol{R}, \boldsymbol{R})-\mathbf{C 1 2 C 1 8}$ and rac-C12C18 moderate the denser packing. Consequently, excessive aggregation is hindered in small aggregates.

\section{Conclusion}

We prepared three gelators, each of chiral and racemic types, based on trans-1,2-diaminocyclohexane. One is chiral 
and racemate containing $n$-dodecanoylamino groups as the same substituents. The others are chiral and racemates containing structurally different substituents: 10-undecenoylamino and 2-heptylundecanoylamino groups as the substituents in one case, and 5-hydroxypentanoylamino and 2-heptylundecanoylamino as the substituents in the other case. Results of gelation tests with eight solvents demonstrated that the order of gelation ability to form stable gels is $(\boldsymbol{R}$, $R)-\mathrm{C} 12 \mathrm{C} 12 \approx(R, R)-\mathrm{C} 12 \mathrm{C} 18 \approx(R, R)-\mathrm{C} 5 \mathrm{H} 18>$ rac-C12C18 $\approx$ rac-C5H18 $>$ rac-C12C12. Although the gels formed by rac-C12C12 were so unstable that they crystallized after several hours, both rac-C12C18 and rac-C5H18, which included different substituents, formed very stable gels. The gelation abilities were investigated using three-component mixed solvents of $\mathrm{HDEH}$, liquid paraffin, and D5 (66 combinations). ( $R, R)-\mathrm{C12C18},(R, R)-\mathrm{C} 5 \mathrm{H} 18$, rac-C12C18, and rac-C5H18 all formed translucent gels with all of the investigated mixed solvent combinations. The thermal stabilities of the gels were evaluated on the basis of their phase-transition temperatures. The highest thermal stability was observed for gels formed by $(\boldsymbol{R}, \boldsymbol{R})-\mathbf{C} 5 \mathbf{H 1 8}$, and the second-most thermally stable gels were formed by rac-C5H18. The transmittance of gels composed of a mixture of HDEH, liquid paraffin, and D5 was studied. The order of transparency of gels over the total investigated wavelength band was $(\boldsymbol{R}$, $R)-\mathrm{C} 12 \mathrm{C} 18 \approx(R, R)-\mathrm{C} 5 \mathrm{H} 18>(R, R)-\mathrm{C} 12 \mathrm{C} 12 \approx \operatorname{rac}-\mathrm{C} 5 \mathrm{H} 18>$ rac-C12C18 $\approx r a c-C 12 C 12$. The viscoelastic behavior of gels of a three-component mixed solvent was studied via rheology measurements. The $(\boldsymbol{R}, \boldsymbol{R})-\mathbf{C 5 C} 18$ and $(\boldsymbol{R}, \boldsymbol{R})-\mathbf{C} 12 \mathrm{H} 18$ with different substituents formed the harder gels compared with $(\boldsymbol{R}$, $R)$-C12C12. Electron microscopy images of $(R, R)-C 12 C 18$ showed fine thread-like aggregates with nearly homogeneous $\sim 26 \mathrm{~nm}$ diameters. The widths of fibers of rac-C12C18 ranged from 42 to $50 \mathrm{~nm}$. The fibers formed by racemates were thicker than those formed by enantiomers. The left-handed helicity was confirmed in the gels formed by toluene and isopropyl myristate in $(\boldsymbol{R}, \boldsymbol{R})$-C12C12. Helical aggregates in gels formed by $(\boldsymbol{R}, \boldsymbol{R})$-C12C18 were not observed by TEM; however, the appearance of a strong $\mathrm{CD}$ band supported the existence of helical aggregates in the gels. The IFT/GIFT results for $(\boldsymbol{R}$, $R)-C 12 C 18$ and rac-C12C18 indicate that the presence of a long rod-like or strand structure is most likely and that these were aggregated to some extent in an aligned manner, but not a crystalline-like structure. $(\boldsymbol{R}, \boldsymbol{R})$-C12C12 formed rod-like aggregates at low concentrations, which then transformed into hexagonal aggregates at $40 \mathrm{mg} \mathrm{mL}{ }^{-1}$. The forward scattering intensities of $(\boldsymbol{R}, \boldsymbol{R})-\mathrm{C12C18}$ and rac-C12C18 demonstrated that the different substituents in $(\boldsymbol{R}, \boldsymbol{R})-\mathrm{C12C18}$ and rac-C12C18 moderate the denser packing. The restrain of excessive aggregation results in small aggregates. Finally, we clarified the importance of different substituents in diamides based on racemic trans-1,2-diaminocyclohexane on physical gelation. A concept of beingness of structurally different substituents will be helpful in development and molecular design of new gelators.

\section{Acknowledgement}

The present research was supported in part by JSPS KAKENHI Grant Number JP15K05623.

\section{Supporting Information}

Figure S1, Figure S2, Figure S3, Figure S4, and Figure S5

\section{References}

1. P. Terech, R. G. Weiss, Chem. Rev. 1997, 97, 3133.
2. J. H. Esch, B. L. Feringa, Angew. Chem., Int. Ed. 2000, 39, 2263.

3. L. A. Estroff, A. D. Hamilton, Chem. Rev. 2004, 104, 1201.

4. P. Dastidar, Chem. Soc. Rev. 2008, 37, 2699.

5. V. Praveen, S. Babu, C. Vijayakumar, A. Ajayaghosh, Bull. Chem. Soc. Jpn. 2008, 81, 1196.

6. S. Banerjee, R. K. Das, U. Maitra, J. Mater. Chem. 2009, 19, 6649 .

7. M. Suzuki, K. Hanabusa, Chem. Soc. Rev. 2009, 38, 967.

8. M. Suzuki, K. Hanabusa, Chem. Soc. Rev. 2010, 39, 455.

9. J.-L. Li, X.-Y. Liu, Adv. Funct. Mater. 2010, 20, 3196.

10. G. John, B. V. Shankar, S. R. Jadhav, P. K. Vemula, Langmuir 2010, 26, 17843.

11. H. Svobodová, V. Noponen, E. Kolehmainen, E. Sievänen, RSC Adv. 2012, 2, 4985.

12. S. S. Babu, S. Prasanthkumar, A. Ajayaghosh, Angew. Chem., Int. Ed. 2012, 51, 1766.

13. A. Y.-Y. Tam, V. W.-W. Yam, Chem. Soc. Rev. 2013, 42, 1540 .

14. J. Raeburn, A. Z. Cardoso, D. J. Adams, Chem. Soc. Rev. 2013, 42, 1543.

15. G. Yu, X. Yan, C. Han, F. Huang, Chem. Soc. Rev. 2013, 42, 6697.

16. M. D, Segarra-Maset, V. J. Nebot, J. F. Miravet, B. Escuder, Chem. Soc. Rev. 2013, 42, 7086.

17. S. S. Babu, V. K. Praveen, A. Ajayaghosh, Chem. Rev. 2014, 114, 1973.

18. D. K. Kumar, J. W. Steed, Chem. Soc. Rev. 2014, 43, 2080.

19. V. K. Praveen, C. Ranjith, N. Armaroli, Angew. Chem., Int. Ed. 2014, 53, 365.

20. M. Liu, L. Zhang, T. Wang, Chem. Rev. 2015, 15, 7304.

21. Y. Lan, M. G. Corradinia, R. G. Weiss, S. R. Raghavanc, M. A. Rogers, Chem. Soc. Rev. 2015, 44, 6035.

22. Low Molecular Mass Gelators; Design, Self-Assembly, Function, ed. F. Fages. Springer, Berlin Heidelberg New York, 2005.

23. T. Tachibana, T. Mori and K. Hori, Bull. Chem. Soc. Jpn. 53, 1714-1719 (1980).

24. S. Yamamoto, J. Chem. Soc. Jpn. Ind. Chem. Soc. 1943, 46, 779; Chem. Abstr. 1952, 46, 7047 i.

25. F. Placin, M. Colomés, J. Desvergne, Tetrahedron Lett. 1997, 38, 2665.

26. L. Lu, R. G. Weiss, Chem. Commun. 1996, 2029.

27. J. van Esch, R. M. Kellog, B. L. Feringa, Tetrahedron Lett. 1997, 38, 281.

28. K. Hanabusa, C. Koto, M. Kimura, H. Shirai, Chem. Lett. 1997, 429.

29. M. Ikeda, M. Takeuchi, S. Shinkai, Chem. Commun. 2003, 1354.

30. M. Shirakawa, N. Fujita, S. Shinkai, J. Am. Chem. Soc. 2003, 125, 9902.

31. K. Hanabusa, J. Tange, Y. Taguchi, T. Koyama, H. Shirai, Chem. Commun. 1993, 390.

32. K. Hanabusa, M. Yamada, M. Kimura, H. Shirai, Angew. Chem., Int. Ed. Engl.1996, 35, 1949.

33. K. Hanabusa, H. Kobayashi, M. Suzuki, M. Kimura, H. Shirai, Colloid Polym. Sci. 1998, 276, 252.

34. O. Wallach, Justus Liebigs Ann. Chem. 1895, 286, 90.

35. C. P. Brock, W. B. Schweizer, J. D. Dunitz, J. Am. Chem. Soc. 1991, 113, 9811.

36. C. M. Marson, I. Schwarz, Tetrahedron Lett. 2000, 41, 8999.

37. J. A. Lake, Acta Cryst. 1967, 23, 191.

38. D. Orthaber, A. Bergmann, O. Glatter, J. Appl. 
Crystallogr. 2000, 33, 218

39. M. J. Taylor, S. Tanna, T. S. Sahota, B. Voermans, Eur. J. Pharm. Biopharm. 2006, 62, 94.

40. X.-F. Wei, R.-Y. Bao, Z.-Q. Cao, W. Yang, B.-H. Xie, M.-B. Yang, Macromolecules 2014, 47, 1439.

41. Y. Shi, M. Wang, C. Ma, Y. Wang, X. Li, G. Yu, Nano Lett. 2015, 15, 6276

42. J. H. Jung, Y. Ono, K. Hanabusa, S. Shinkai, J. Am. Chem. Soc. 2000, 122, 5008.

43. O. Glatter, G. Fritz, H. Lindner, J. Brunner-Popela, R. Mittelbach, R. Strey, S.U. Egelhaaf, Langmuir 2000, 16, 8692.

44. O. Glatter, O. Kratky, Small-Angle X-ray Scattering; Academic: London, (1982).

45. T. Sato, T. Akahane, K. Amano, R. Hyodo, K. Yanase, T. Ogura, J. Phys. Chem. B, 2016, 120, 5444.

46. L.K. Shrestha, S.C. Sharma, T. Sato, O. Glatter, K. Aramaki, J. Colloid Interface Sci. 2007, 316, 815.

47. L.K. Shrestha, T. Sato, K. Aramaki, Phys. Chem. Chem. Phys. 2009, 11, 4251.

48. O. Glatter, J. Appl. Crystallogr. 1977, 10, 415.

49. O. Glatter, J. Appl. Crystallogr. 1980, 13, 577.

50. J. Brunner-Popela, O. Glatter, J. Appl. Crystallogr. 1977, 30, 431.

51. B. Weyerich, J. Brunner-Popela, O. Glatter, J. Appl. Crystallogr. 1999, 32, 197.

52. L.S. Ornstein, F. Zernicke, Proc. K. Ned. Akad. Sci. 1914, 17, 793.

53. S.H. Chen, Annu. Rev. Phys. Chem. 1986, 37, 351

54. A. J. C. Wilson, Arithmetic Crystal Classes and Symmophic Space Groups. International Tables for Crystallography. Kluwer Academic: London, 1992; Vol. C, DOI:10.1107/97809553602060000575. 


\section{Graphical Abstract}

\section{Characteristics of Gelation by Amides based on trans-1,2-Diaminocyclohexane: The Importance of Different Substituents}

Haruka Nakagawa, Mamoru Fujiki, Takaaki Sato, Masahiro Suzuki, Kenji Hanabusa*

$<$ Summary $>$

Although a racemic rac-C12C12 containing the same undecanoyl groups had no gelation ability due to the crystalline character, rac-C12C18 including different substituents worked as a good gelator. It could form stable gels in various solvents.

$<$ Diagram $>$

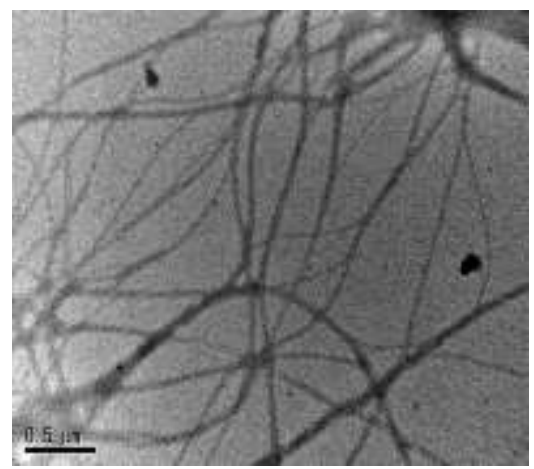

TEM image of gel of rac-C12C18 in the mixture of HDEH, liquid paraffin, and D5.

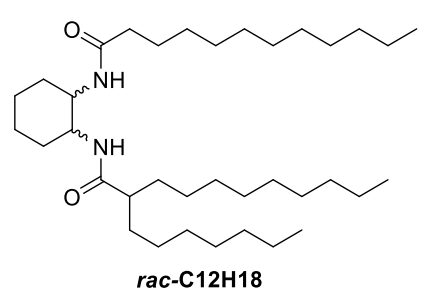

